\section{Fish figures hint at past extinctions}

Contrary to the popular saying, there are not plenty of fish in the sea. But why? Perhaps because a huge number of species became extinct in ancient times, say Greta Carrete Vega and John Wiens at Stony Brook University in New York.

Marine environments cover about $70 \%$ of Earth's surface but contain only $15-25 \%$ of all estimated species. To find out why, Vega and Wiens studied actinopterygian (ray-finned) fish - which encompass 96\% of Earth's fish species - in marine and freshwater environments.

They found that both environments were similarly rich in actinopterygian species, even through the marine environment is much larger and has greater primary productivity. They also discovered that all extant marine actinopterygians descend from a freshwater ancestor, suggesting that ancient extinctions have robbed the seas of their species. Proc. R. Soc. B http://dx.doi. org/10.1098/rspb.2012.0075 (2012)

\section{CLIMATE CHANGE}

\section{More super-hot} summers ahead

Summer temperatures once considered exceptionally high have, in recent decades, become more frequent $\$$ across the United States as a result of anthropogenic climate change.

Philip Duffy, currently at the Lawrence Livermore National Laboratory in Livermore, California, and Claudia Tebaldi at the National Center for Atmospheric Research in Boulder, Colorado, compared summer temperature extremes from 1950 to 1999 with simulations derived from 16 global climate models. Model projections suggest that US summer temperatures will continue to rise as the century progresses. Even in regions that have warmed relatively little so far, the chances of extreme temperatures - seen only once in 20 years in the second half of the past century - will be at least $70 \%$ in any given year by 2064 .

Clim. Change http://dx.doi. org/10.1007/s10584-0120396-6 (2012)

\section{MATERIALS SCIENCE}

\section{Six-faced particles}

Janus particles, named after the two-faced Roman god, are solid particles of two halves, each with different physical properties and with applications that include drug delivery. But Shoji Takeuchi and his colleagues at the University of Tokyo have gone beyond Janus's two faces and made gel spheres with up to six distinct sections. The particles are about 100 micrometres in diameter and, when each section is permeated with different fluorescent nanobeads, look like beach balls.

To make them, the researchers injected dyed sodium alginate solutions down a multi-barrelled capillary tube, which they then centrifuged. This forced the liquid streams out to form droplets composed of multiple liquids. The droplets fell into a waiting bath of calcium chloride, turning them to gel before the component solutions could mix.

The researchers also used their method to produce Janus particles holding magnetic particles and living cells in their separate halves (pictured). Adv. Mater. http://dx.doi. org/10.1002/adma.201102560 (2012)

COMMUNITY CHOICE

The most viewed papers in science

\title{
T-cell retreat in chronic hepatitis C
}

\section{- highly Read \\ on www.rupress. org in January}

After acute infection with hepatitis $\mathrm{C}$, some people recover whereas others develop chronic disease. Contrary to expectation, the latter group launches the same initial immune response against the virus as the former.

Recovery from hepatitis $\mathrm{C}$ infection was thought to be heralded by a broad response by $\mathrm{CD} 4^{+} \mathrm{T}$ cells, which had not previously been detected in most patients with chronic disease. But Georg Lauer of Massachusetts General Hospital in Boston and his colleagues detected these cells in the blood samples of 31 patients with acute infection, including 13 who later advanced to chronic disease. The researchers cultured the immune cells and, with the aid of sensitive fluorescent labelling, showed that the cells later disappeared from samples taken from the chronic disease group.

Early antiviral therapy can prevent the loss of CD4 $\mathrm{T}$ cells, suggesting a possible means by which to prevent the development of chronic infection.

J. Exp. Med. 209, 61-75 (2012)
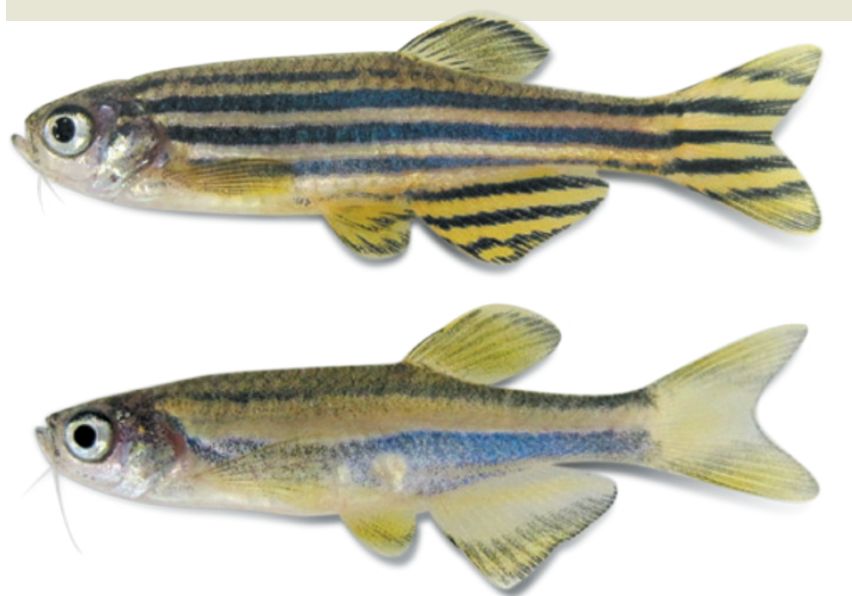

\section{ZOOLOGY}

\section{Stripes from shifting cells}

Repulsion between pigment cells helps to explain how adult zebrafish develop the stripes for which they are named.

Shigeru Kondo and his colleagues at Osaka University in Japan looked at cultured black melanophore and yellow xanthophore pigment cells from the animals (pictured top). They found that when the black pigment cells came into contact with the yellow ones, their membrane potential changed, shifting the charge at the cells' surface. In $60 \%$ of such encounters, the melanophores moved away from the xanthophores. However, in mutant fish that lack regular stripes (bottom), the two cell types always stayed in contact with each other.

The authors say that although repulsion alone is not sufficient to explain pattern formation, repulsion could be involved in the stripes' development.

Science 335, 677 (2012)

\section{ONATURE.COM}

For the latest research published by Naturevisit:

www.nature,com/latestresearch 